\title{
Oxidized silver cups can skew oxygen isotope results of small samples
}

\author{
Man-Yin Tsang ${ }^{1}$ (D), Weiqi $\mathrm{Yao}^{2}$ and Kevin Tse ${ }^{3}$ \\ ${ }^{1}$ University of Toronto, The University of Hong Kong, ${ }^{2}$ University of Toronto, and ${ }^{3}$ The University of Hong Kong \\ *Corresponding author. E-mail: my.tsang@mail.utoronto.ca
}

(Received 31 January 2020; Revised 03 March 2020; Accepted 04 March 2020).

\begin{abstract}
One of the commonly used analytical approaches for measuring oxygen isotope ratios $\delta^{18} \mathrm{O}$ of solids (organic and inorganic) is to pyrolyze the samples to gaseous phases and then send the gas into an isotope ratio mass spectrometer system. Solid samples for $\delta^{18} \mathrm{O}$ measurements are usually stored in silver cups because of its low reactivity towards oxygen and other oxidants. Samples in silver cups can be dropped directly into the carbon column of the pyrolysis furnace. However, the silver cups can tarnish and then be oxidized over a prolonged storage period. We find that while a small amount of silver oxides does not affect measurements with appreciable sample sizes, it can skew isotope results of small samples. We thus recommend careful storage of samples in silver cups to minimize oxidation, such as under an air-isolated condition, and avoiding prolonged storage for accurate $\delta^{18} \mathrm{O}$ measurements.
\end{abstract}

Keywords: Oxygen isotope; mass spectrometer; silver oxidation

\section{Introduction}

Solid samples for oxygen isotope $\delta^{18} \mathrm{O}$ measurements are commonly stored in silver cups. However, silver cups tarnish $\left(\mathrm{Ag}_{2} \mathrm{~S}\right)$ upon exposure to $\mathrm{H}_{2} \mathrm{~S}$ in the air even at parts-per-billion concentrations of $\mathrm{H}_{2} \mathrm{~S}$ (Franey et al., 1985), especially near the opening of the cups where they are pressed to avoid the samples from falling out (Fig. 1). Other than $\mathrm{Ag}_{2} \mathrm{~S}$, a small amount of $\mathrm{AgO}, \mathrm{Ag}_{2} \mathrm{O}, \mathrm{Ag}_{2} \mathrm{SO}_{3}, \mathrm{Ag}_{2} \mathrm{SO}_{4}$ can also form on the cup (Franey et al., 1985; Sanders et al., 2015), particularly in the presence of ozone in the air (Wiesinger et al., 2013). Some laboratories store the silver cups in ovens to avoid moisture, which can speed up the oxidation process. Even if the silver cups are stored in room conditions, they can still turn yellow after storage for about a year.

\section{Objective}

Silver oxides or sulfate on silver cups can potentially affect the $\delta^{18} \mathrm{O}$ measurements. In this study, we explore this problem and the circumstance that the oxidized silver cups become a concern. We measure the $\delta^{18} \mathrm{O}$ of silver cups that appear pale yellow, in order to identify if oxidation of the cups can skew $\delta^{18} \mathrm{O}$ measurements of small solid samples. We use measurements of oxygen isotope ratios from $\mathrm{BaSO}_{4}$ standards to illustrate the effects of the oxidized silver cups. 


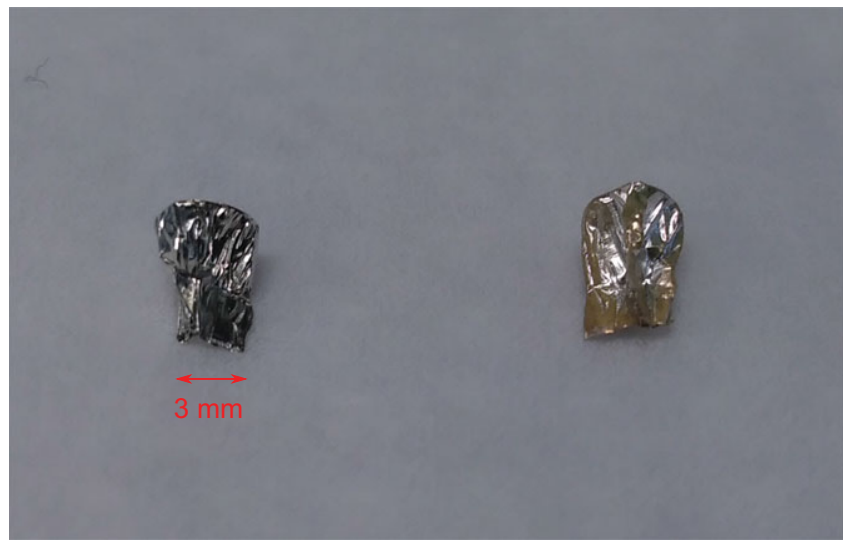

Figure 1. A new silver cup (left) and an old silver cup that has held samples for over a year in room conditions (right). Notice the old cup has turned slightly yellow, especially at its pressed opening.

\section{Methods}

We put two silver cups into an $80^{\circ} \mathrm{C}$ oven to speed up the process of oxidation. The cups turn to pale yellow after a month. We also have a silver cup that has sat in room conditions for over a year and turned pale yellow. We then measure the $\delta^{18} \mathrm{O}$ of these three silver cups with a Hekatech high-temperature pyrolysis furnace and a continuous flow isotope ratio mass spectrometer system (CF-IRMS, Finnigan MAT 253 in continuous flow mode using a Conflo III open split interface). Before the measurements, the system passed the linearity test, background test and zero test. In the same run, we measure the $\delta^{18} \mathrm{O}$ of IAEA-SO-5 $\mathrm{BaSO}_{4}$ standard to compare the oxygen peak sizes from standard sulfate and the silver cups. $\delta^{18} \mathrm{O}$ values (V-SMOW) are calibrated with international standards for oxygen isotopes: IAEA-SO-5, USGS-32, NBS-127 and IAEA-SO- 6 . The standard deviation of the measurements is $0.18 \%$.

\section{Results}

The three yellow silver cups give small peaks of oxygen in the mass spectrum results (Fig. 2a). The cups stored in an $80^{\circ} \mathrm{C}$ oven show amplitude- 28 of only $141 \mathrm{mV}$ and $112 \mathrm{mV}$. The amplitude- 28 of the cup stored in room conditions for over a year is larger, at $219 \mathrm{mV}$. $\delta^{18} \mathrm{O}$ values $(9.4 \%$, $11.5 \%$, $-4.5 \%$ ) from such small amounts of oxygen are not accurate and are only for reference here.

In the same run, $\sim 200 \mu \mathrm{g}$ of $\mathrm{BaSO}_{4}$ (IAEA-SO-5, about $27 \%$ of the mass is from O) produces an amplitude- 28 at about $6,500 \mathrm{mV}$, and $43 \mu \mathrm{g} \mathrm{BaSO}_{4}$ at about 1,500 $\mathrm{mV}$ (Fig. 2b). This means when $200 \mu \mathrm{g}$ $\mathrm{BaSO}_{4}$ is used for BaSO4- $\delta{ }^{18} \mathrm{O}$ measurements, the oxides from the silver cup contribute less than $\sim 3.5 \%$ of the oxygen being measured. However, when only $43 \mu \mathrm{g} \mathrm{BaSO}$ is measured, the oxides from the silver cup can contribute roughly $13 \%$ of the oxygen.

\section{Discussions}

Our experiment demonstrates that when using conventional sample sizes (e.g., $200 \mu \mathrm{g} \mathrm{BaSO}_{4}$ ), the oxidized silver cups are not a concern for the accurate measurements of $\delta^{18} \mathrm{O}$. However, when only a small sample is available, or the sample is impure so the oxygen content is lower than expected, the oxides on the silver cups can skew the $\delta^{18} \mathrm{O}$ results.

The scale of the skewness can vary, depending on the time of storage, the quantities of oxygen compounds and the isotope compositions of oxidants. For instance, $\delta^{18} \mathrm{O}$ of both atmospheric $\mathrm{O}_{2}$ and $\mathrm{H}_{2} \mathrm{O}$ vary according to environmental conditions (e.g., Craig, 1961; Klots \& Benson, 1963; Benson \& Krause, 1980). These oxidants on silver cups will skew $\delta^{18} \mathrm{O}$ results differently. 

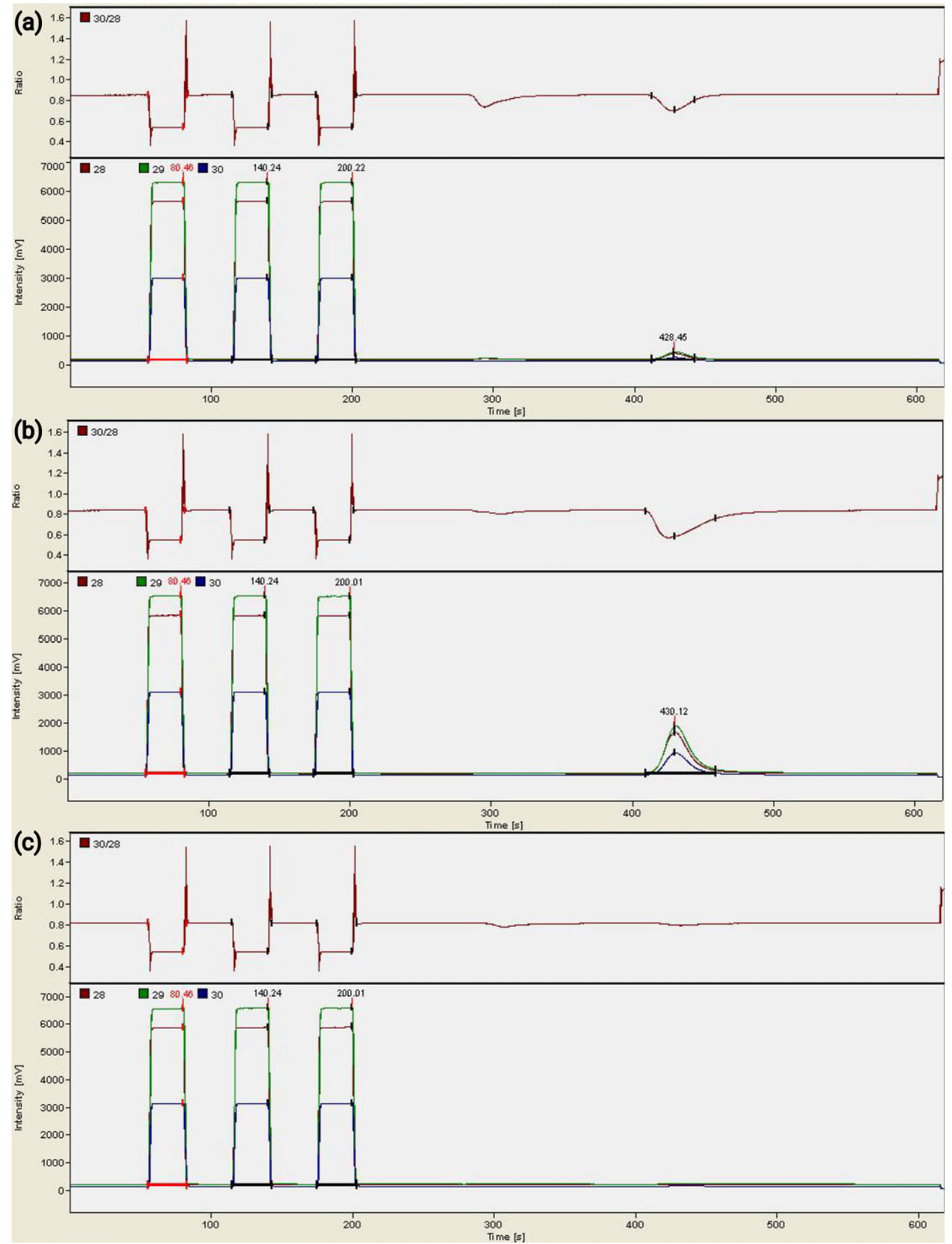

Figure 2. Mass spectrum results from the mass spectrometer. In each mass spectrum, the first three peaks at the left are from the reference gas (tuned for measuring $200 \mu \mathrm{g}$ of $\mathrm{BaSO}_{4}$ ) and the fourth peak is the peak of the oxygen from the sample. (a) An old, pale yellow silver cup gives a small oxygen peak. (b) $43 \mu \mathrm{g}$ of $\mathrm{BaSO}_{4}$ gives an oxygen peak larger than that in (a). (c) In comparison, a new silver cup gives no oxygen peaks in the mass spectrum. 
If prolonged storage of samples in silver cups is unavoidable, simple methods to postpone the oxidation process include vacuum-sealing the sample holders and storing the samples in a desiccator. Storing samples in an argon- or nitrogen-filled environment may be considered for storage over an extensive period. The laboratory condition, e.g., whether natural gas is present, matters as natural gas contains a minor amount of $\mathrm{H}_{2} \mathrm{~S}$. An effective and clean heating, ventilation, and air conditioning (HVAC) system of the laboratory should also help lessen the oxidation problem.

\section{Conclusions}

Our results demonstrate that if small or impure samples are measured for their oxygen isotope compositions, oxidized silver cups that hold the samples can skew the measurements. Our finding suggests that proper sample storage is also an important step for accurate isotope measurements. When small sample sizes are unavoidable, we recommend shortening the storage period with the silver cups and vacuum-sealing the sample holders to delay the oxidation process.

Acknowledgements. We thank the reviewer for the useful comments that help improve this manuscript.

Author Contributions. MYT and KT designed the study and performed the experiments. MYT, WY and KT analyzed the data and wrote the article.

Funding Information. This research received no specific grant from any funding agency, commercial or not-for-profit sectors.

Data Availability Statement. The data that support the findings of this study are available in Supplementary Material.

Conflict of Interest Declaration. MYT, WY and KT declare none.

Supplementary Materials. To view supplementary material for this article, please visit http://dx.doi.org/10.1017/exp.2020.15.

\section{References}

Benson, B. B., \& Krause, D. (1980). The concentration and isotopic fractionation of gases dissolved in fresh-water in equilibrium with the atmosphere. 1. Oxygen. Limnology and Oceanography, 25, 662-671. https://doi.org/10.4319/ lo.1980.25.4.0662.

Craig, H. (1961). Isotopic variations in meteoric waters. Science, 133, 1702-1703. https://doi.org/10.1126/science.133.3465.1702.

Franey, J. P., Kammlott, G. W., \& Graedel, T. E. (1985). The corrosion of silver by atmospheric sulfurous gases. Corrosion Science, 25, 133-143. https://doi.org/10.1016/0010-938X(85)90104-0.

Klots, C. E., \& Benson, B. B. (1963). Isotope effect in the solution of oxygen and nitrogen in distilled water. The Journal of Chemical Physics, 38, 890-892. https://doi.org/10.1063/1.1733778.

Sanders, C. E., Verreault, D., Frankel, G. S., \& Allen, H. C. (2015). The role of sulfur in the atmospheric corrosion of silver. Journal of the Electrochemical Society, 162, C630-C637. https://doi.org/10.1149/2.0051512jes.

Wiesinger, R., Martina, I., Kleber, C., \& Schreiner, M. (2013). Influence of relative humidity and ozone on atmospheric silver corrosion. Corrosion Science, 77, 69-76. https://doi.org/10.1016/j.corsci.2013.07.028.

Cite this article: Tsang M-Y, Yao W, Tse K (2020). Oxidized silver cups can skew oxygen isotope results of small samples Experimental Results, 1, e12, 1-6. https://doi.org/10.1017/exp.2020.15 


\title{
Peer Reviews
}

\section{Reviewing editor: Dr. Il-Nam Kim}

Incheon National University, Marine Science, 119 Academy-ro, 5-540, Incheon, Korea (the Republic of), 22012

This article has been accepted because it is deemed to be scientifically sound, has the correct controls, has appropriate methodology and is statistically valid, and met required revisions.

\section{doi:10.1017/exp.2020.15.prl}

\section{Review 1: Oxidized silver cups can skew oxygen isotope results of small samples}

\section{Reviewer: Zhengyu Xia}

Lehigh University, Earth and Environmental Sciences

Date of review: 03 March 2020

Published online:

\begin{abstract}
(C) The Author(s) 2020. This is an Open Access article, distributed under the terms of the Creative Commons Attribution licence http://creativecommons.org/licenses/by/4.0/), which permits unrestricted re-use, distribution, and reproduction in any medium, provided the original work is properly cited.
\end{abstract}

Conflict of interest statement. Reviewer declares none

\section{Comment}

Comments to the Author: The authors study a well-defined laboratory question and the paper is wellwritten. A few comments:Line 12 measuring oxygen isotope ratio (d18O) OF THE SOLIDS (ORGANIC AND INORGANIC)Line 27 OTHER THAN Ag2SLine 75-76, can result in THAT ... COULD SKEW d18O results differentlyLine 126, MASS spectrumIn some newly built laboratory building, the air is controlled by HVAC system as that I expect $\mathrm{H} 2 \mathrm{~S}$ and $\mathrm{O} 3$ concentrations are monitored and should be even less than a trace value, so in my experience the silver cups do not seem to decay in color. Also, rather than consider the mass balance in $\mathrm{d} 18 \mathrm{O}$, why do not just measure the same standard $\mathrm{BaSO} 4$ sample in a separate run in a new silver cup and a tarnished cup and see how much permille of $\mathrm{d} 18 \mathrm{O}$ is skewed?

\section{Score Card}

\section{Presentation}

5.0

Is the article written in clear and proper English? (30\%)

Is the data presented in the most useful manner? (40\%)

Does the paper cite relevant and related articles appropriately? (30\%)

Context

Does the abstract correctly embody the content of the article? (25\%)

Does the introduction give appropriate context? (25\%)

Is the objective of the experiment clearly defined? (25\%) 
Are the limitations of the experiment as well as the contributions of the experiment clearly outlined? (20\%) 